\title{
Adsorption Kinetics of Cupric Ions on Mixture of Modified Corn Stalk and Modified Tomato Waste
}

\author{
Sareh Vafakhah*, Mohammad E. Bahrololoom, Mohsen Saeedikhani \\ Department of Materials Science and Engineering, Shiraz University, Shiraz, Iran \\ Email: *vafakhah.sareh@gmail.com
}

How to cite this paper: Vafakhah, S., Bahrololoom, M.E. and Saeedikhani, M. (2016) Adsorption Kinetics of Cupric Ions on Mixture of Modified Corn Stalk and Modified Tomato Waste. Journal of Water Resource and Protection, 8, 1238-1250.

http://dx.doi.org/10.4236/jwarp.2016.813095

Received: October 30, 2016

Accepted: November 25, 2016

Published: November 28, 2016

Copyright $\odot 2016$ by authors and Scientific Research Publishing Inc. This work is licensed under the Creative Commons Attribution International License (CC BY 4.0).

http://creativecommons.org/licenses/by/4.0/

\begin{abstract}
The water crisis is an increasingly severe global problem that may be reduced by reusing wastewater after suitable treatment methods. Nowadays, biosorption is one of the main parts of environmental technology which could adsorb heavy metals. This paper describes the adsorption of Copper(II) ions from aqueous solution using a mixture of corn stalk and tomato waste which were oxidized with nitric acid. Kinetic and isotherm studies were carried out by studying the effects of parameters such as concentration dosage, time and $\mathrm{pH}$. It was found that the maximum sorption capacity of the mixture of modified corn stalk and modified tomato waste $\left(q_{m}=25 \mathrm{mg} / \mathrm{g}\right)$ was higher than the modified corn stalk $\left(q_{m}=20.8 \mathrm{mg} / \mathrm{g}\right)$. Analysis indicated that pseudo-second-order kinetics controlled the adsorption rate and it has been proposed to correlate the experimental data well.
\end{abstract}

\section{Keywords}

Corn Stalk, Tomato Waste, Biosorption, Copper Ions Removal

\section{Introduction}

Most heavy metal ions are deleterious in excessive concentrations. Heavy metal ions and their toxic effects have become a major world concern, causing harm to human life and the environment. This pollution is released to soil and water by human industrial activities and has considerable effects by joining the food chain [1] [2]. Various industries produce and discharge wastes containing different heavy metal ions into the environment. These include mining and smelting, surface finishing industry, energy and fuel production, fertilizer and pesticide industry, leatherworking, photography and electric appliance manufacturing. Thus, metals cause serious environmental pollution, threatening human health and ecosystem [3]. 
The agricultural application of sewage sludge is limited by organic pollutants and heavy metal ions because they tend to accumulate along the food chain and bring potential risks to animals and humans [1] [2].

According to the World Health Organization (WHO), U.S. Environmental Protection Agency (USEPA) and many other government environmental protection agencies, it has been set the Maximum Contaminant Levels (MCLs) for the heavy metals which exist in drinking water as well as trade effluent [4]. Industrial wastewater treatment containing low concentrations of pollutants is becoming increasingly important [5] [6]. Copper is one of the broadly used materials which cause neurotoxicity, jaundice and liver and kidney toxicity. It may be found as a dangerous contaminant in food, especially shellfish, liver, mushrooms, nuts and chocolate [7] [8] [9]. There are different methods for the removal of heavy metals including chemical precipitation, reverse osmosis, ion exchange, and coagulation [1] [10] [11]. However, the application of such methods is limited due to some reasons such as incomplete metal removal, energyintensive, economically expensive, and generation of secondary waste products [12] [13]. Adsorption is the most efficient and versatile method for removing any contaminants like heavy metal, especially if accompanied with appropriate regeneration steps. This solves the problem of sludge disposal and changes the system to more economically viable, especially if low-cost adsorbents are used [13] [14] [15]. Agricultural byproducts usually are composed of basic constituents like lignin and cellulose and may also include other polar functional groups of lignin, which includes alcohols, aldehydes, ketones, carboxylic, phenolic and ether groups. The advantage of these groups is the ability to bind heavy metal ions by donation of their electron pair to form complexes with the metal ions in solution [16].

Corn is one of the largest products in the world. It includes by-products such as corn cob, corn husk, corn leaf and corn stalk which are abundant agriculture residues, but most are burnt without utilization [17]. In addition, there is another agricultural byproduct, tomato waste, which is abundantly available in Iran. If an adsorbent is a byproduct or waste material from another industry, is abundant in nature, or requires little processing, it can be assumed as "low cost" adsorbent [18].

The main objective of this research was to study the mixture of modified corn stalk as mentioned in our previous research [1] and tomato waste to determine their adsorption capacity in removing $\mathrm{Cu}$ (II) ions from simulated contaminated samples. The adsorption equilibrium was expressed using Langmuir and Freundlich models. Also, kinetic parameters for removal of copper ions from wastewaters using corn stalk/tomato waste as an adsorbent were investigated via adsorption isotherms and kinetic models. Experimental parameters affecting the biosorption process such as $\mathrm{pH}$, time and ion concentration of solution for Copper(II) removal were optimized.

\section{Materials and Methods}

\subsection{Adsorbent Preparation}

Raw corn stalk (RCS) and tomato waste were obtained from a farm near Shiraz, Iran. 
After removing the leaves from the stalk and separation of impurities from tomato waste, the biomasses were cut into small slices. The samples were then ground through a 70-mesh sieve to achieve a uniform particle size. Then each powder was separately washed three times with distilled water and was dried in an oven at $50^{\circ} \mathrm{C}$ until it reaches a constant weight.

Leyva-Ramos [19] method was used for oxidation of the corn stalk and the tomato waste. Each of the biosorbents was oxidized separately with nitric acid solutions as a chemical activator by adding $20 \mathrm{~g}$ of each to $100 \mathrm{ml}$ of the acid solution in a flask. The concentration of the acid solution was $1 \mathrm{M}$. The whole solution containing the corn stalk and the tomato waste was heated for $2 \mathrm{~h}$ keeping the temperature at $50^{\circ} \mathrm{C}$, inconsistent with the author's previous work [1]. To prepare the modified corn stalk (MCS)/ Modified tomato waste (MTW) mixture, the solutions were added together drop by drop. The solution was mechanically stirred for $48 \mathrm{~h}$ to disperse the particles into each other homogeneously.

Afterward, the whole solution was allowed to cool and drained to separate the biosorbents from the solution. The mixture was washed several times with distilled water until the $\mathrm{pH}$ of the distilled water ceased to change during washing. It was finally dried in an oven at $50^{\circ} \mathrm{C}$ for $24 \mathrm{~h}$. At last, the biosorbent was stored in plastic bottles for further use.

\subsection{Characterization of Adsorbents}

In this work the $\mathrm{pH}$ at point zero charge $\left(\mathrm{pH}_{\mathrm{pzc}}\right)$ of the MCS/MTW mixture was determined by the $\mathrm{pH}$ drift method used by Yang et al. [5], with the modification that sodium chloride was used as an inert electrolyte. Before measurement of $\mathrm{pH}$ drift, the biosorbent was completely washed with water followed by dilute sodium hydroxide $(0.01 \mathrm{M})$ to neutralize any free nitric acid that may have remained. Finally, the adsorbent soaked in $\mathrm{HCl}$ for $24 \mathrm{~h}$. After filtration, the "enriched" mixture was washed with distilled water, and it was then air-dried. This procedure was done to ensure the removal of any potential effects on $\mathrm{pH}$ drift due to the dissolution of salts in the MCS/ MTW mixture. The $\mathrm{pH}$ of test solutions was adjusted in $0.005 \mathrm{M} \mathrm{NaCl}$ using $0.5 \mathrm{M} \mathrm{HCl}$ or $0.5 \mathrm{M} \mathrm{NaOH}$. A $0.06 \mathrm{~g}$ of the prepared biosorbent was measured and added to $20 \mathrm{~mL}$ of the $\mathrm{pH}$-adjusted solution in a plastic capped vial and equilibrated for $24 \mathrm{~h} \mathrm{[5].} \mathrm{The}$ final $\mathrm{pH}$ was measured using a $\mathrm{pH}$ meter (model 827-metrohm) and plotted against the initial $\mathrm{pH}$. The $\mathrm{pH}_{\mathrm{PZC}}$ was found by the point that curve crosses the $\mathrm{pH}_{\mathrm{i}}=\mathrm{pH}_{\mathrm{f}}$ line.

\subsection{Batch Experiment and Analysis}

The aqueous solution of heavy metal was prepared with dissolving $\mathrm{CuSO}_{4}$ in distilled water. The adsorption isotherm experiments were performed at $220 \mathrm{rpm}$ on the magnetic stirrer with $1 \mathrm{~g}$ of adsorbent in Erlenmeyer flask containing $100 \mathrm{ml}_{\text {of }} \mathrm{CuSO}_{4}$ solution with the initial concentration of 25,50 and $100 \mathrm{mg} / \mathrm{L}$ at $298 \mathrm{~K}$ and $\mathrm{pH}=2-6$, as metal ions were expected to form metal hydroxide at $\mathrm{pH}$ values greater than 6 regarding to the chosen concentrations [20]. The $\mathrm{pH}$ of the solution was adjusted with adding 
$0.01 \mathrm{M}$ nitric acid or potassium hydroxide. In order to determine the amount of $\mathrm{Cu}$ ions in the solution, an AA-800 atomic absorption spectrophotometer made by PerkinElmer Company was used with limit of detection (LOD) equal to $1 \mathrm{ppb}$ (the detection limit (according to IUPAC) is the smallest concentration or absolute amount of analyte that has a signal significantly larger than the signal arising from a reagent blank).

\subsection{Sorption Experiments}

Define abbreviations and acronyms the first time they are used in the text, even after they have been defined in the abstract. Abbreviations such as IEEE, SI, MKS, CGS, sc, $\mathrm{dc}$, and rms do not have to be defined. Do not use abbreviations in the title or heads unless they are unavoidable. To determine the amount of $\mathrm{Cu}$ (II) ion adsorbed on the biosorbents used in this study, Equation (1) [3] was used:

$$
q_{e}=\left[\left(C_{0}-C_{e}\right) V\right] / M
$$

where $q_{e}$ is the adsorption capacity per unit mass of the adsorbents $(\mathrm{mg} / \mathrm{g})$ while $C_{0}$ is the initial concentration of the metal ion $(\mathrm{mg} / \mathrm{l})$ and $C_{e}$ is the concentration of the metal ions after equilibrium, $V$ and $M$ are volume of the solution (l) and mass of adsorbent (g), respectively.

At predetermined intervals of time, solutions were analyzed for the final concentration of $\mathrm{Cu}^{2+}$. At specific time $t(\mathrm{~min})$, the amount of adsorption $q_{t}(\mathrm{mg} / \mathrm{g})$, was calculated by Equation (2) [21]:

$$
q_{t}=\left[\left(C_{0}-C_{t}\right) V\right] / M
$$

where $C_{t}\left(\mathrm{mg} \cdot \mathrm{l}^{-1}\right)$ is concentration of $\mathrm{Cu}^{2+}$ at time $t$.

\subsection{Equilibrium Isotherms}

Adsorption isotherm is used to indicate interaction of adsorbate with the adsorbent materials. It is necessary to establish the most suitable correlations for the equilibrium data of the system for optimizing the design of adsorption process to remove $\mathrm{Cu}$ (II) ion. The Langmuir and the Freundlich isotherms were used to correlating the equilibrium data for Copper(II) removal [13].

One of the most important models of monolayer adsorption is Langmuir isotherm which is based on the assumption of a fixed number of adsorption sites, and each site can hold only one adsorbate molecule (the adsorbed layer is one molecule in thickness). All sites are same, and there is not any interaction between the adsorbed molecules [22] [23].

The linearized form of Langmuir isotherm is (Equation (3)) [19]:

$$
\left(C_{e} / q_{e}\right)=\left(1 / q_{m} b\right)+\left(C_{e} / q_{m}\right)
$$

where $q_{e}$ is the amount of adsorbed ions per unit mass of adsorbent at equilibrium (mg/g adsorbent), $C_{e}$; the concentration of adsorbate remaining in the solution at equilibrium $(\mathrm{mg} / \mathrm{L}), b$; the constant related to adsorption net enthalpy, $q_{m}$ is the maximum adsorption capacity $(\mathrm{mg} / \mathrm{g})$. In addition, constants $b$ and $q_{m}$ can be evaluated from the 
plot of $C_{e} / q_{e}$ versus $C_{e}$.

The dimensionless factor $R_{L}$, called separation factor is another characteristic parameter of the Langmuir isotherm which estimates the degree of suitability and can be obtained using the following equation (Equation (4)) [7] [24]:

$$
R_{L}=\left(1 /\left(1+b C_{0}\right)\right)
$$

Suitability of the isotherm can be understood from $R_{L}$. The values less than unity show that the sorption of metal ions to the adsorbents particles is optimum and the sorption process is favorable. Its value indicates the type of isotherm to be irreversible $\left(R_{L}=0\right)$, favorable $\left(0<R_{L}<1\right)$, linear $\left(R_{L}=1\right)$ or unfavorable $\left(R_{L}>1\right)$.

The prepared solutions and adsorbents were left in contact with each other until equilibrium was reached. A sample was taken to determine the final $\mathrm{Cu}$ (II) concentration in different times at the intervals of the experiment, to evaluate the equilibrium time. After $2 \mathrm{~h}$, the adsorbent was separated from the solution using a filter. The solution was then analyzed using an atomic absorption spectrophotometer to determine the equilibrium concentration of the $\mathrm{Cu}(\mathrm{II})$ ions.

Another important isotherm is Freundlich isotherm which proposes a monolayer sorption with a heterogeneous energetic distribution of active sites, accompanied by interactions between adsorbed molecules. Freundlich isothermis an empirical relation between the concentration of a solute on the surface of an adsorbent to the concentration of the solute in the liquid with which it is in contact. It can be expressed as Equation (5):

$$
q_{e}=K_{f} *\left(C_{e}\right) 1 / n
$$

A logarithmic form can also be expressed as Equation (6):

$$
\ln q_{e}=b_{F} * \ln C_{e}+\ln K_{f}
$$

where $K_{f}$ is the Freundlich constant and $b_{F}$ is the Freundlich exponent.

\subsection{Sorption Kinetics}

The two main types of sorption kinetic models, i.e., pseudo-first and pseudo-secondorder models were considered in order to examine a suitable rate of adsorption and investigate the controlling mechanism of adsorption process [7] [25].

Porous adsorbents adsorb any solute in four main stages: (1) transfer of solute from the bulk solution to the solution nearby the adsorbent, (2) transport of solute from surrounding surface of the adsorbents to the surface of adsorbent, (3) transfer of solute from adsorbent surface to the active internal sites, and finally (4) binding of the solute molecules to the available adsorption sites which present on the internal surfaces of the adsorbent [26].

The pseudo-first-order reaction equation of Lagergren [7] [27] is vastly used for the adsorption of liquid/solid system based on the capacity of adsorbents. This model assumes that the rate of surface site's change concentration is proportional to the amount of unoccupied surface sites which is remained [28]. This model can be expressed as Equation (7): 


$$
\log \left(q_{e}-q_{t}\right)=\log \left(q_{e}\right)-\left[\left(k_{1} t\right) / 2.303\right]
$$

where $q_{e}$ and $q_{t}$ are the amounts of adsorbed metal ions per unit mass of biosorbent at the equilibrium $(\mathrm{mg} / \mathrm{g})$ and at time $t$, respectively and $k_{1}$ is the Lagergren rate constant of the first-order adsorption $\left(\mathrm{min}^{-1}\right)$.

The pseudo-second-order model is based on the assumption that the rate is proportional to the square of the number of remaining free surface sites [28]. The linearized second-order kinetic model is given by Equation (8):

$$
t / q_{t}=\left[1 /\left(k_{2} q_{e}^{2}\right)\right]+t / q_{e}
$$

where $k_{2}$ is the rate constant for the second-order adsorption kinetics ( $\left.\mathrm{g} / \mathrm{mg} \mathrm{min}\right)$.

\section{Results and Discussion}

\subsection{Point of Zero Charge}

The point of zero charge the $\mathrm{pH}_{\mathrm{PZC}}$ of any adsorbent is a very important characteristic that determines the $\mathrm{pH}$ at which the surface has net electrical neutrality [5]. The surface acidity and basicity are important criteria because it describes the surface chemistry of the adsorbents. The combined influence of all the functional groups of the adsorbents determines $\mathrm{pH}_{\mathrm{pzc}}[21]$.

In this work, the $\mathrm{pH}$ drift method was employed to determine this parameter. As shown in Figure 1, the curve cuts the $\mathrm{pH}_{\mathrm{i}}=\mathrm{pH}_{\mathrm{f}}$ line at 3.8.

According to the author's previous research [1], $\mathrm{pH}_{\mathrm{pzc}}$ of the present research was greater than the $\mathrm{pH}_{\mathrm{pzc}}$ of the Modified Corn Stalk $(3.8>1.96)$. Therefore, this result revealed that the MCS has more acidic sites than the MCS/MTW mixture. Therefore, the optimum $\mathrm{pH}$ must be chosen greater than 4.5 which was found in the previous research.

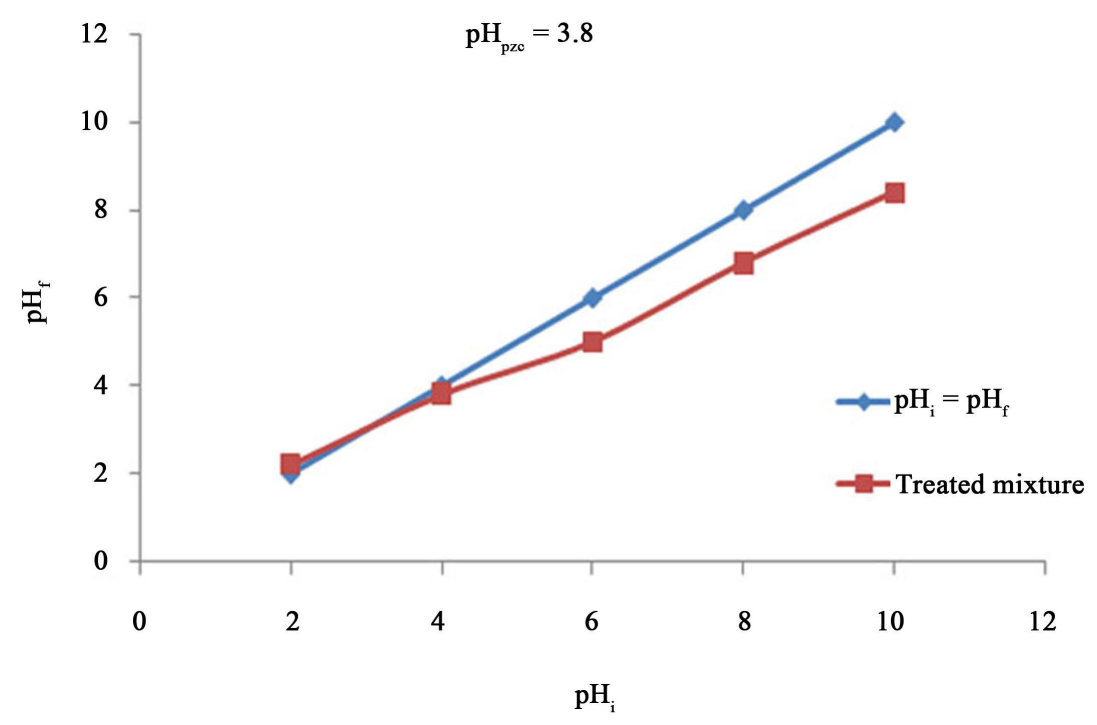

Figure 1. Suspension test for determining the $\mathrm{pH}$ of point of zero charge of equal portions of modified corn stalk (MCS)/Modified Waste Tomato (MWT) mixture by $\mathrm{pH}$ drift method. 


\subsection{Effect of Solution $\mathrm{pH}$}

The $\mathrm{pH}$ of the aqueous solution has been reported to present a significant influence on the adsorptive uptake of $\mathrm{Cu}^{2+}$ ions due to its impact on both the surface binding-sites of the adsorbent and the ionization process of the metal ions [21] [29] [30].

The $\mathrm{pH}$ of the point of zero charge measurement on these adsorbents supports this observation, below which the surface is net positively charged and unable to bind $\mathrm{Cu}^{2+}$ ions [5]. The effect of initial $\mathrm{pH}$ on adsorption was determined at different $\mathrm{pH}$ values (2 - 6). $\mathrm{T}$ he effects of initial $\mathrm{pH}$ on the adsorption of $\mathrm{Cu}(\mathrm{II})$ by the adsorbent mixture are presented in Figure 2.

At lower $\mathrm{pH}$ values ( $\mathrm{pH} 2.0$ ), the $\mathrm{H}_{3} \mathrm{O}^{+}$ions are competed with the $\mathrm{Cu}(\mathrm{II})$ for the exchange site in the adsorbent [31]. Because $\mathrm{H}_{3} \mathrm{O}^{+}$occupied the sites on adsorbents, heavy metal ions remained in solution. Another factor which restricts adsorption is that the hydroxyl group also combines easily with $\mathrm{H}_{3} \mathrm{O}^{+}$ions or it has a reaction with functional groups. At high $\mathrm{pH}$ values ( $\mathrm{pH}$ 6.0), the concentration of $\mathrm{Cu}$ (II) was higher than $\mathrm{H}_{3} \mathrm{O}^{+}$ ions, so that more exchange sites were provided for heavy metal ions [17] [29]. As shown in Figure 2, the highest capacity was reached at $\mathrm{pH}=6$. In addition, the $\mathrm{pH}$ of the solution decreased after $\mathrm{Cu}$ (II) binding, suggesting that with the binding of $\mathrm{Cu}$ (II) on the biomass, protons are released into the solution from the biomass.

Ion removal is highly concentration-dependent, the more concentrated the solution, the better the adsorption [17] [32]. Therefore, the solution concentration was chosen $100 \mathrm{mg} / \mathrm{l}$ to study the effect of $\mathrm{pH}$.

\subsection{Effect of Initial Concentration on Cu(II) Biosorption}

Biosorption of $\mathrm{Cu}$ (II) ions by MCS/MTW mixture as a function of the initial metal ion concentration was presented in Figure 3 for $1 \mathrm{~g} / 100 \mathrm{ml}$ biosorbent dosage with $\mathrm{pH}$ of 6. It was clear that copper biosorption capacity of MCS/MTW mixture increased as the initial metal ion concentration increased, while the removal efficiency of $\mathrm{Cu}$ (II)

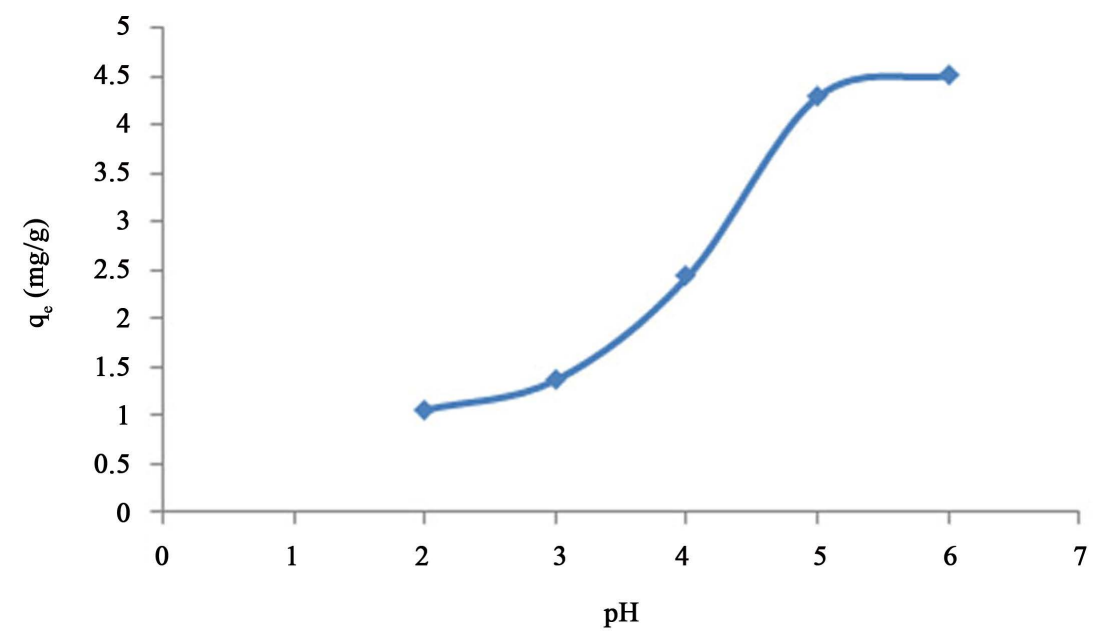

Figure 2. Effect of $\mathrm{pH}$ on Copper(II) biosorption using equal portions of MCS/ MWT equal portion mixture particle. 


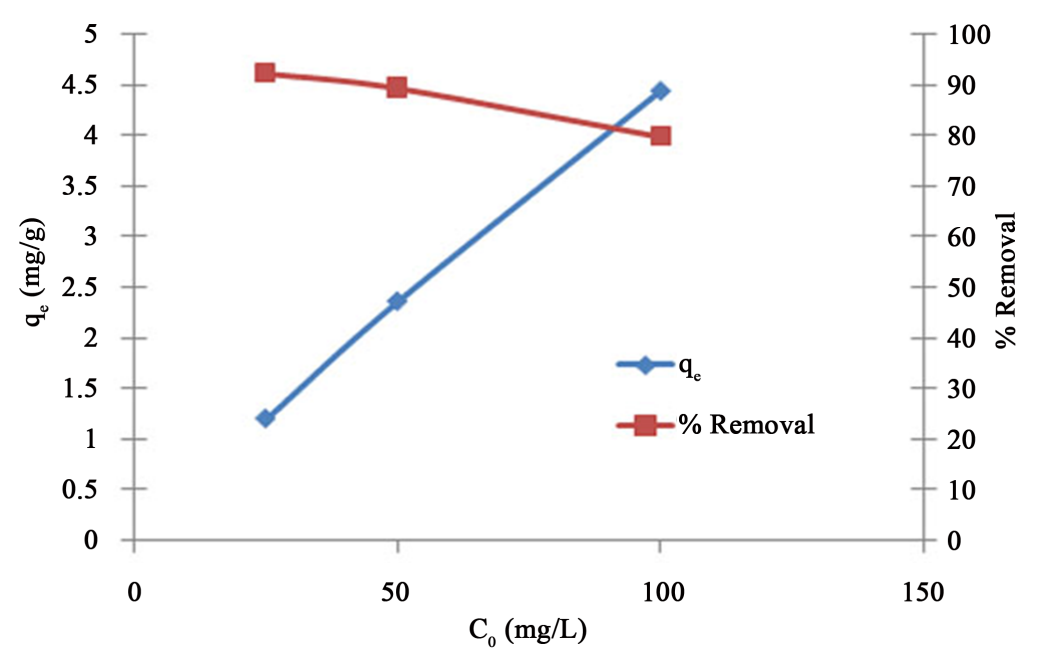

Figure 3. Effect of initial $\mathrm{Cu}(\mathrm{II})$ concentration ( $\mathrm{pH}$ : 6 , biosorbent dosage: 1 $\mathrm{g} / 100 \mathrm{~mL}$, temperature: $298 \mathrm{~K}$, contact time: $120 \mathrm{~min}$ ).

decreased. The concentration gradient of biosorption was the driving force to overcome mass transfer resistances between the adsorbent and adsorption medium which increased biosorption capacity. A drop in the removal efficiency of $\mathrm{Cu}$ (II) may be due to the saturation of surface area and active sites of adsorbent [13] [33]. The maximum uptake capacity of the adsorbent was obtained in the concentration of $100 \mathrm{mg} / \mathrm{L}$, and it was reached to $4.64 \mathrm{mg} / \mathrm{g}$.

\subsection{Adsorption Equilibrium Studies}

Langmuir constants of MCS/MTW mixture, $q_{m}(\mathrm{mg} / \mathrm{g})$ and $b(\mathrm{~L} / \mathrm{mg})$ were obtained from the slope and intercept of the linear plot of $C_{e} / q_{e}$ versus $C_{e}$ (Figure 4), respectively. The Langmuir model correlation coefficient and constants were: $R^{2}=0.987, q_{m}=25$ $\mathrm{mg} / \mathrm{g}, b=0.0039 \mathrm{~L} / \mathrm{mg}$. The $R_{L}$ values were found to be between 0.71 and 0.91 , indicating that the biosorption of Copper(II) on MCS/MTW mixture was favorable (Figure 5).

Also with the linear plot of $\ln q_{e}$ versus $\ln C_{e}$, Using the Freundlich isotherm model, the values of $b_{F}$ and $K_{F}$ were obtained and reported as, $R^{2}=0.998, n=1.11 \mathrm{~g} / \mathrm{L}, K_{F}=$ $0.12 \mathrm{mg} / \mathrm{g}$.

The sorption data for the investigated biosorbent showed a good fit with the Freundlich isotherm model and it had a better fit than the Langmuir isotherm model (0.987). It should be mentioned that both the Langmuir and Freundlich isotherms have good conformity. Figure 4 and Figure 6 show the Langmuir isotherm model and the Freundlich isotherm model, respectively, for sorption of $\mathrm{Cu}$ (II) ions onto these investigated biosorbents.

It was found that the adsorption capacity of modified corn stalk increased from 20.8 $\mathrm{mg} / \mathrm{g}$ to $25 \mathrm{mg} / \mathrm{g}$ by using modified tomato waste as an adding biosorbent.

Furthermore, $\mathrm{Cu}(\mathrm{II})$ was favorably biosorbed by MCS/MTW mixture due to $n$ value obtained from the Freundlich isotherm which was higher than 1.0 [13] [34]. 


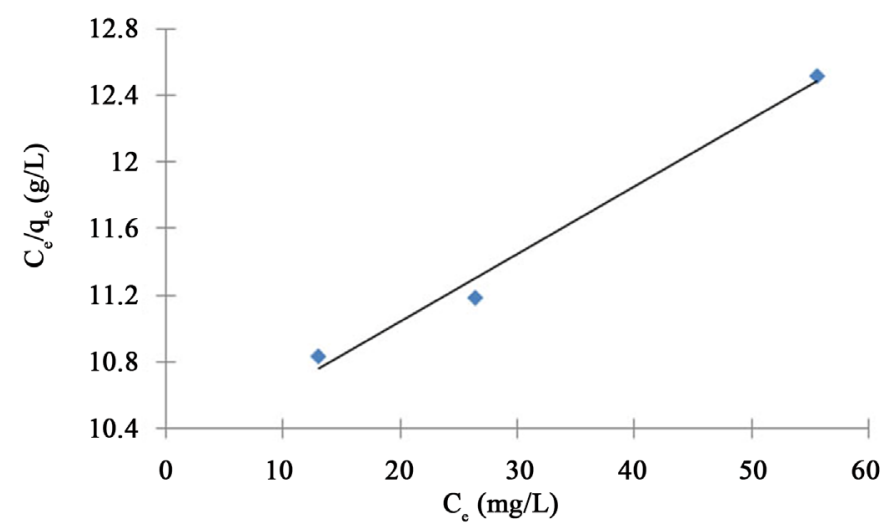

Figure 4. Langmuir isotherm model of Copper(II) biosorption onto equal portions of MCS/ MWT mixture particle.

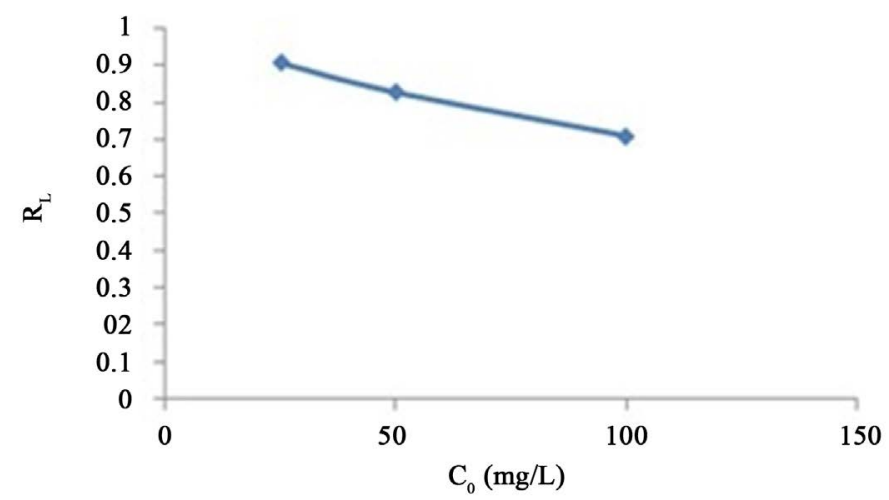

Figure 5. Effect of $\mathrm{Cu}(\mathrm{II})$ initial concentration on dimensionless separation factor $R_{L}$.

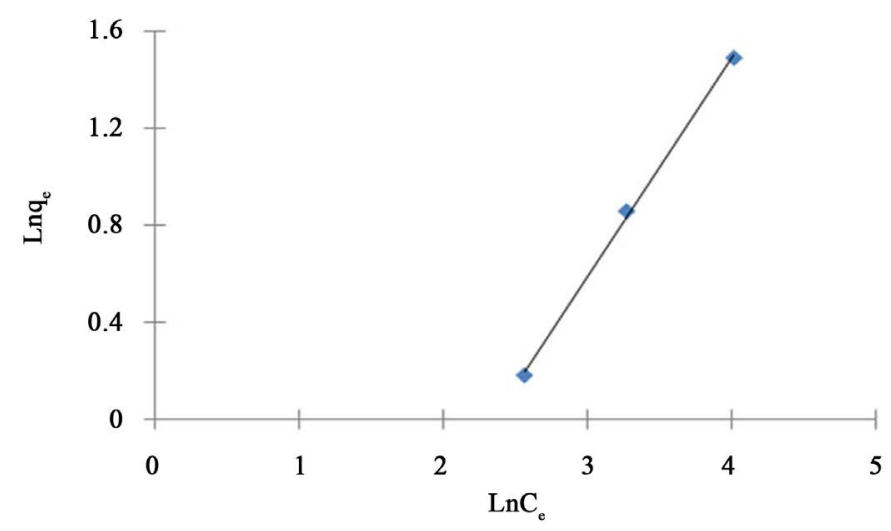

Figure 6. Freundlich isotherm of model of Copper(II) biosorption onto equal portions of MCS/MWT mixture particle.

\subsection{Kinetic Studies}

Sorption kinetic studies were conducted by adding $1 \mathrm{~g}$ of MCS/MTW mixture to $100 \mathrm{ml}$ of $\mathrm{Cu}$ (II) solution with initial concentrations of 25, 50 and $100 \mathrm{mg} / \mathrm{l}$ and initial $\mathrm{pH}$ of 6 . The solution was poured into a flask and placed in a shaking incubator at a speed of 220 
rpm to measure the adsorption of MCS/MTW mixture at different time intervals at 298 K. The straight-line plots of $\log \left(q_{e}-q_{t}\right)$ against $t$ and of $t / q_{t}$ against $t$ were used to determine the rate constants and correlation coefficients for the first and second-order kinetic models, respectively (Figure 7 and Figure 8).

As observed, the higher values $R^{2}$ (correlation coefficient) are resulted in the pseudosecond-order model in all the initial concentrations over the entire region (Figure 8). The pseudo-second order model demonstrated the best fit. In addition, as shown in Table 1 the first-order model failed to provide a realistic estimate of $q_{e}$. On the other hand, the calculated $q_{e}$ based on the second-order model is in good accordance with the experimental one. This result showed that chemisorptions mechanism most likely controlled the biosorption of $\mathrm{Cu}(\mathrm{II})$ onto MCS/MTW mixture [13].

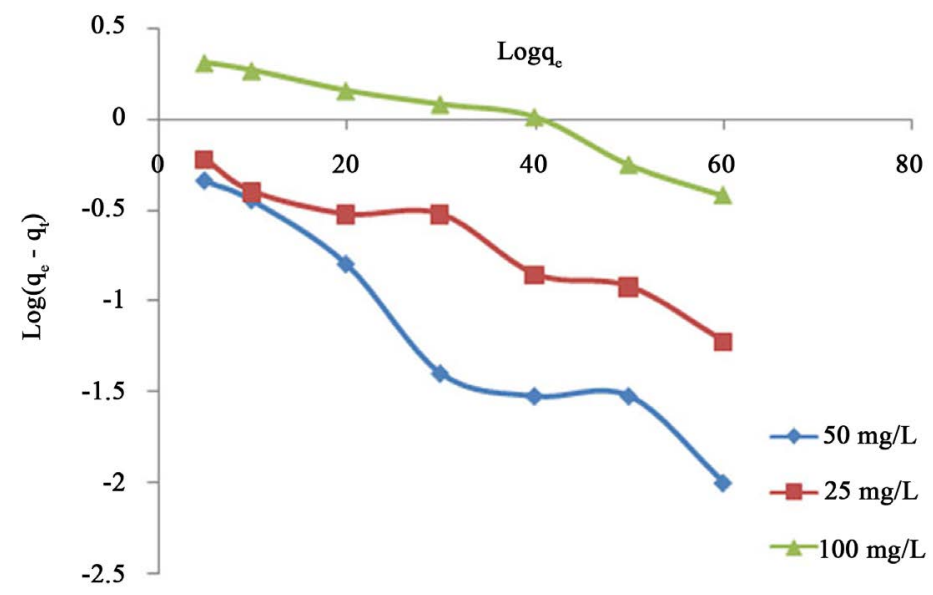

Figure 7. Pseudo-first order rate constants for adsorption of the $\mathrm{Cu}(\mathrm{II})$ ions onto equal portions of MCS/MWT mixture ( $\mathrm{pH}=6, M=1 \mathrm{~g}, T=$ $298 \mathrm{~K}, V=100 \mathrm{~mL})$.

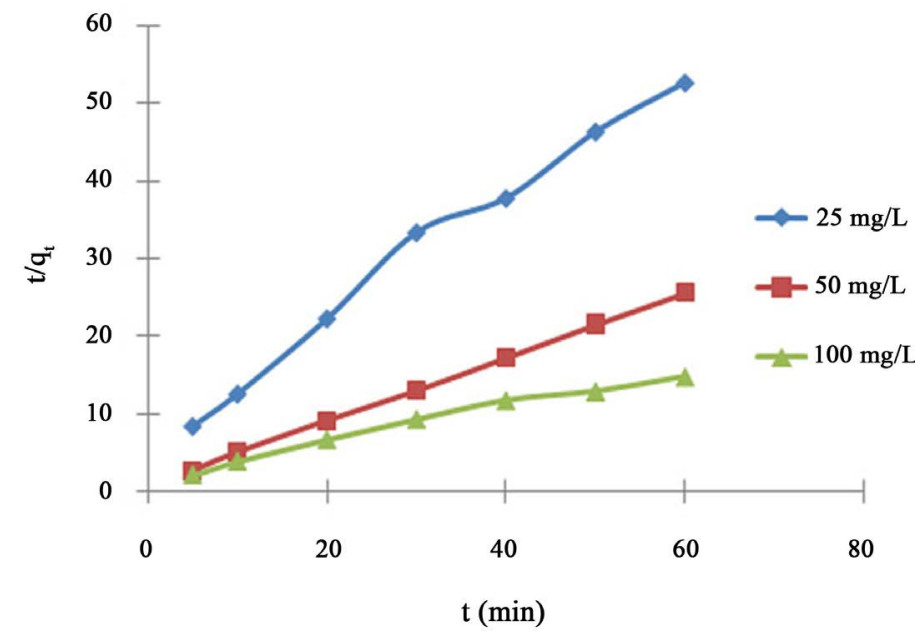

Figure 8. Pseudo-second order rate constants for adsorption of the $\mathrm{Cu}(\mathrm{II})$ ions onto equal portions of MCS/MWT mixture ( $\mathrm{pH}=6, M=1$ g, $T=298 \mathrm{~K}, V=100 \mathrm{~mL}$ ). 
Table 1. Pseudo-first and second order rate constants for adsorption of $\mathrm{Cu}(\mathrm{II})$ ions onto equal portions of MCS/MWT mixture ( $\mathrm{pH}=6, M=1 \mathrm{~g}, V=100 \mathrm{~mL}$ and $T=298 \mathrm{~K}$ ).

\begin{tabular}{cccccccc}
\hline$C_{0}$ & $\boldsymbol{q}_{e}$ exp & \multicolumn{2}{c}{ Pseudou-First order rate constants } & \multicolumn{3}{c}{ Pseudou-Second order rate constants } \\
\cline { 3 - 7 }$(\mathrm{mg} / \mathrm{L})$ & $(\mathrm{mg} / \mathrm{g})$ & $\begin{array}{c}\boldsymbol{q}_{e} \mathrm{cal} \\
(\mathrm{mg} / \mathrm{g})\end{array}$ & $\begin{array}{c}K_{1} \\
(1 / \mathrm{min})\end{array}$ & $R^{2}$ & $\begin{array}{c}\boldsymbol{q}_{e}, \mathrm{cal} \\
(\mathrm{mg} / \mathrm{g})\end{array}$ & $\begin{array}{c}K_{2} \\
(\mathrm{~g} / \mathrm{mg} \cdot \mathrm{min})\end{array}$ & $R^{2}$ \\
\hline 25 & 1.2 & 0.69 & 0.03 & 0.951 & 1.23 & 0.12 & 0.98 \\
50 & 2.36 & 0.58 & 0.06 & 0.942 & 2.42 & 0.24 & 0.99 \\
100 & 4.44 & 2.61 & 0.027 & 0.950 & 4.36 & 0.03 & 0.98 \\
\hline
\end{tabular}

\section{Conclusion}

This study reveals that sorption experiments of the $\mathrm{Cu}(\mathrm{II})$ ions from aqueous solutions onto a mixture of corn stalk and tomato waste which were oxidized with nitric acid were used successfully. The sorption studies indicate that metal ion uptake was $\mathrm{pH}$ dependent and maximum biosorption of Copper(II) ion was obtained $4.54 \mathrm{mg} / \mathrm{g}$ at $\mathrm{pH}$ =6. It was clear that the adsorption capacity of modified corn stalk increased from 20.8 $\mathrm{mg} / \mathrm{g}$ to $25 \mathrm{mg} / \mathrm{g}$ by using modified tomato waste as adding biosorbent. The adsorption process best followed the pseudo-second-order model, which is in agreement with chemical sorption being the rate-controlling step. The present study reveals that these cheap and easily available materials have the excellent adsorbing capability for copper removal from industrial effluents.

\section{Acknowledgements}

The authors would like to thank department of materials science and engineering at Shiraz University for providing laboratory facilities and Dr. M. A. Zare for providing atomic adsorption experiments.

\section{References}

[1] Vafakhah, S., Bahrololoom, M.E., Bazarganlari, R. and Saeedikhani, M. (2014) Removal of Copper Ions from Electroplating Effluent Solutions with Native Corn Cob and Corn Stalk and Chemically Modified Corn Stalk. Journal of Environmental Chemical Engineering, 2, 356-361. https://doi.org/10.1016/j.jece.2014.01.005

[2] Zafarani, H.R., Bahrololoom, M.E., Noubactep, C. and Tashkhourian, J. (2015) Green Walnut Shell as a New Material for Removal of Cr(VI) Ions from Aqueous Solutions. Desalination and Water Treatment, 55, 431-439. https://doi.org/10.1080/19443994.2014.917986

[3] Wang, J. and Chen, C. (2009) Biosorbents for Heavy Metals Removal and Their Future. Biotechnological Advances, 27, 195-226. https://doi.org/10.1016/j.biotechadv.2008.11.002

[4] He, J. and Chen, J.P. (2014) A Comprehensive Review on Biosorption of Heavy Metals by Algal Biomass: Materials, Performances, Chemistry, and Modeling Simulation Tools. Bioresoureces Technology, 160, 67-78. https://doi.org/10.1016/j.biortech.2014.01.068

[5] Nasiruddin Khan, N. and Farooq Wahab, M. (2007) Characterization of Chemically Modified Corncobs and Its Application in the Removal of Metal Ions from Aqueous Solution. Journal of Hazardous Materials, 141, 237-244.

https://doi.org/10.1016/j.jhazmat.2006.06.119 
[6] Uzunoğlu, D., Gürel, N., Özkaya, N. and Özer, A. (2014) The Single Batch Biosorption of Copper(II) Ions on Sargassum acinarum. Desalination and Water Treatment, 52, 15141523. https://doi.org/10.1080/19443994.2013.789403

[7] Bazarganlari, R., Zafarani, H.R., Bahrololoom, M.E. and Nemati, A. (2014) Removal of $\mathrm{Cu}$ (II) Ions from Aqueous Solutions by Low-Cost Natural Hydroxyapatite/Chitosan Composite: Equilibrium, Kinetic and Thermodynamic Studies. Journal of Taiwan Institute of Chemical Engineers, 45, 1642-1648. https://doi.org/10.1016/j.jtice.2013.11.009

[8] Yu, B., Zhang, Y., Shukla, A., Shukla, S.S. and Dorris, K.L. (2000) The Removal of Heavy Metal from Aqueous Solutions by Sawdust Adsorption-Removal of Copper. Journal of Hazardous Materials, 80, 33-42. https://doi.org/10.1016/S0304-3894(00)00278-8

[9] Varma, V.G. and Misra, A.K. (2016) Equilibrium and Kinetic Studies on the Adsorption of Copper onto Paddy Straw Powder. Desalination and Water Treatment, 57, 13081-13090. https://doi.org/10.1080/19443994.2015.1057536

[10] Ahmadpour, A., Tahmasbi, M., Rohanibastami, T. and Besharati, A. (2009) Rapid Removal of Cobalt Ion from Aqueous Solutions by Almond Green Hull. Journal of Hazardous Materials, 166, 925-930. https://doi.org/10.1016/j.jhazmat.2008.11.103

[11] Zafarani, H.R., Bahrololoom, M.E., Javidi, M., Shariat, M.H. and Tashkhourian, J. (2014) Removal of Chromate Ion from Aqueous Solutions by Sponge Iron. Desalination and Water Treatment, 52, 7154-7162. https://doi.org/10.1080/19443994.2013.822335

[12] Soetaredjo, F.E., Kurniawan, A., Ki, O.L. and Ismadji, S. (2013) Incorporation of Selectivity Factor in Modeling Binary Component Adsorption Isotherms for Heavy Metals-Biomass System. Chemical Engineering Journal, 219, 137-148.

https://doi.org/10.1016/j.cej.2012.12.077

[13] Yargıç, A.Ş., YarbayŞahin, R.Z., Özbay, N. and Önal, E. (2015) Assessment of Toxic Copper(II) Biosorption from Aqueous Solution by Chemically-Treated Tomato Waste (Solanum lycopersicum). Journal of Cleaner Production, 88, 152-159. https://doi.org/10.1016/j.jclepro.2014.05.087

[14] Bhattacharya, A.K., Naiya, T.K., Mandal, S.N. and Das, S.K. (2008) Adsorption, Kinetics and Equilibrium Studies on Removal of Cr(VI) from Aqueous Solutions Using Different Low-Cost Adsorbents. Chemical Engineering Journal, 137, 529-541.

[15] Varshini, J.S., Das, D. and Das, N. (2015) Optimization of Parameters for Praseodymium(III) Biosorption onto Biowaste Materials Using Response Surface Methodology: Equilibrium, Kinetic and Regeneration Studies. Ecological Engineering, 81, 321-327. https://doi.org/10.1016/j.ecoleng.2015.04.072

[16] Demirbas, A. (2008) Heavy Metal Adsorption onto Agro-Based Waste Materials: A Review. Journal of Hazardous Materials, 157, 220-229. https://doi.org/10.1016/j.jhazmat.2008.01.024

[17] Zheng, L., Dang, Z., Yi, X. and Zhang, H. (2010) Equilibrium and Kinetic Studies of Adsorption of Cd(II) from Aqueous Solution Using Modified Corn Stalk. Journal of Hazardous Materials, 176, 650-656. https://doi.org/10.1016/j.jhazmat.2009.11.081

[18] Wan, W.S. and Hanafiah, M.A.K.M. (2008) Removal of Heavy Metal Ions from Wastewater by Chemically Modified Plant Wastes as Adsorbents: A Review. Bioresource Technology, 99, 3935-3948. https://doi.org/10.1016/j.biortech.2007.06.011

[19] Leyva-Ramos, R., Bernal-Jacome, L.A. and Acosta-Rodriguez, I. (2005) Adsorption of Cadmium(II) from Aqueous Solution on Natural and Oxidized Corncob. Separation and Purification Technology, 45, 41-49. https://doi.org/10.1016/j.seppur.2005.02.005

[20] Vijayaraghavan, K. and Raja, F.R. (2014) Experimental Characterisation and Evaluation of 
Perlite as a Sorbent for Heavy Metal Ions in Single and Quaternary Solutions. Journal of Water Process Engineering, 4, 179-184. https://doi.org/10.1016/j.jwpe.2014.10.001

[21] Güzel, F., Sayğıll, H., Sayğılı, G.A. and Koyuncu, F. (2014) Elimination of Anionic Dye by Using Nanoporous Carbon Prepared from an Industrial Biowaste. Journal of Molecular Liquids, 194, 130-140. https://doi.org/10.1016/j.molliq.2014.01.018

[22] Zheng, W., Li, X., Yang, Q., Zeng, G., Shen, X., Zhang, Y. and Liu, J. (2007) Adsorption of $\mathrm{Cd}(\mathrm{II})$ and $\mathrm{Cu}(\mathrm{II})$ from Aqueous Solution by Carbonate Hydroxyapatite Derived from Eggshell Waste. Journal of Hazardous Materials, 147, 534-539. https://doi.org/10.1016/j.jhazmat.2007.01.048

[23] Zhu, Z. and Li, W. (2013) Efficient Adsorption and Desorption of $\mathrm{Pb}^{2+}$ from Aqueous Solution. Journal of Environmental Chemical Engineering, 1, 838-843. https://doi.org/10.1016/j.jece.2013.07.022

[24] Podder, M.S. and Majumder, C.B. (2016) Predictive Approach for Simultaneous Biosorption and Bioaccumulation of Arsenic by Corynebacterium glutamicum MTCC 2745 Biofilm Supported on $\mathrm{NL} / \mathrm{MnFe}_{2} \mathrm{O}_{4}$ Composite. Journal of Water Process Engineering, 11, 8-31. https://doi.org/10.1016/j.jwpe.2016.03.010

[25] SairamSundaram, C., Viswanathan, N. and Meenakshi, S. (2009) Defluoridation of Water Using Magnesia/Chitosan Composite. Journal of Hazardous Materials, 163, 618-624. https://doi.org/10.1016/j.jhazmat.2008.07.009

[26] Srivastavaa, S., Agrawala, S.B., Mondalb, M.K. (2015) Biosorption Isotherms and Kinetics on Removal of Cr (VI) Using Native and Chemically Modified Lagerstroemia speciosa Bark. Ecological Engineering, 85, 56-66. https://doi.org/10.1016/j.ecoleng.2015.10.011

[27] Lagergren, S. (1898) About the Theory of So-Called Adsorption of Soluble Substances. Kungliga Svenska Vetenskapsakademiens Handlingar, 24, 1-39.

[28] Schiewer, S. and Balaria, A. (2009) Biosorption of $\mathrm{Pb}^{2+}$ by Original and Protonated Citrus Peels: Equilibrium, Kinetics, and Mechanism. Chemical Engineering Journal, 146, 211-219. https://doi.org/10.1016/j.cej.2008.05.034

[29] Oliveira, L.S., Franca, A.S., Alves, T.M. and Rocha, S.D.F. (2008) Evaluation of Untreated Coffee Husks as Potential Biosorbents for Treatment of Dye Contaminated Waters. Journal of Hazardous Materials, 155, 507-512. https://doi.org/10.1016/j.jhazmat.2007.11.093

[30] Yaro, A.S., Al-Hassani, M.H. and Rasheed, H.A.K. (2015) Copper Biosorption Using Local IRAQI Natural Agents. Desalination and Water Treatment, 54, 533-539. https://doi.org/10.1080/19443994.2014.884941

[31] Nazari, A.M., Cox, P.W. and Waters, K. E. (2014) Biosorption of Copper, Nickel and Cobalt Ions from Dilute Solutions Using BSA-Coated Air Bubbles. Journal of Water Process Engineering, 3, 10-17. https://doi.org/10.1016/j.jwpe.2014.07.001

[32] Aydin, H., Bulut, Y. and Yerlikaya, C. (2008) Removal of Copper(II) from Aqueous Solution by Adsorption onto Low-Cost Adsorbents. Journal of Environmental Management, 87, 37-45. https://doi.org/10.1016/j.jenvman.2007.01.005

[33] Zhang, H.L., Lin, Y.M. and Wang, L. (2009) Biosorption of Copper by Calcium Alginate from Excess Activated Sludge. Environmental Technology, 30, 1461-1467. https://doi.org/10.1080/09593330903213853

[34] Hameed, B.H. (2008) Equilibrium and Kinetic Studies of Methyl Violet Sorption by Agricultural Waste. Journal of Hazardous Materials, 154, 204-212.

https://doi.org/10.1016/j.jhazmat.2007.10.010 
Submit or recommend next manuscript to SCIRP and we will provide best service for you:

Accepting pre-submission inquiries through Email, Facebook, LinkedIn, Twitter, etc. A wide selection of journals (inclusive of 9 subjects, more than 200 journals)

Providing 24-hour high-quality service

User-friendly online submission system

Fair and swift peer-review system

Efficient typesetting and proofreading procedure

Display of the result of downloads and visits, as well as the number of cited articles

Maximum dissemination of your research work

Submit your manuscript at: http://papersubmission.scirp.org/

Or contact jwarp@scirp.org 